\title{
CHANGES IN BUCCAL CELLS IN THE ANAEMIAS
}

\author{
BY \\ M. M. BODDINGTON \\ From the Department of Pathology, Churchill Hospital, Headington, Oxford
}

(RECEIVED FOR PUBLICATION DECEMBER 19, 1958)

Morphological abnormalities of the haemopoietic cells in pernicious anaemia have been well known for many years, but it is only recently that attention has been drawn to abnormalities in the epithelial cells. Graham and Rheault (1954) studied the buccal epithelial cells in gastric washings and showed that there was general enlargement of the cytoplasm and of the nucleus, the presence of some cells with much enlarged nuclei, and an increase in the number of cells with two or more nuclei. The nucleus may be hyperchromatic, with unevenly distributed chromatin and a prominent nucleolus, and have an irregular membrane.

Massey and Klayman (1955) and Rubin (1955, 1956) confirmed these findings, and, with Gardner (1956), found that these changes are also present in megaloblastic anaemia not due to vitamin $B_{12}$ deficiency; however, they are not completely specific for megaloblastic anaemia. Changes in various other epithelia from cases with megaloblastic anaemia have been reported by several authors (Boddington and Spriggs, 1959).

Górz-Kardaszewicz (1956), Boen (1957), and Farrant (1958) measured abnormal cells from th? mouth in cases of pernicious anaemia and confirmed that the nucleus in the buccal cells is abnormally enlarged but this is reversible with treatment.

Scarcely any mention has been made of the condition of the tongue in the cases so far examined, and it therefore seems highly relevant to discover whether the cytological changes in buccal cells are dependent upon atrophy of the papillae or on the megaloblastic anaemia. The present study has been made with this end in view.

\section{Material and Methods}

Initially tongue scrapings taken with a glass slide were used for this study, but specimens of saliva later proved more satisfactory. In some cases both types of specimen were examined (Boddington and Spriggs, 1959). Comparison of the average diameters of the cytoplasm and of the nucleus in specimens taken by the two methods in the same patient showed little variation in the general pattern. In all cases the nuclear diameter in saliva was greater than in the tongue smear and in the majority the difference was a significant one.

Saliva also made possible a direct comparison with the buccal cells seen in gastric washings. In 10 cases the average diameters in saliva showed close agreement with those in gastric washings taken at the same time. The tendency was towards smaller cells and nuclei in the gastric washings, but not in all cases.

In this paper only the results obtained from saliva are reported. Specimens were taken from 59 patients of whom 18 were diagnosed as pernicious anaemia by the usual criteria, 11 as other megaloblastic anaemias (due to pregnancy, five cases, steatorrhoea, two cases, total gastrectomy, one case, nutritional deficiency, one case, carcinomatosis, one case, and phenobarbitone treatment for epilepsy, one case). Twenty had iron-deficiency anaemia, and 10 cases had abnormal tongues not associated with anaemia. Twenty-three patients had papillated tongues and in the rest the papillae were atrophied to a greater or lesser degree. Specimens from 10 people of different age groups were used as controls.

Specimens were collected by asking the patient to spit several times into a container. The saliva was centrifuged and two films made from the deposit either with a wire loop or by spreading between the two slides; these were immediately "wet-fixed" in ether-alcohol or ethyl alcohol containing $3 \%$ acetic acid for staining by the Papanicolaou technique.

The slides were examined through the $1 / 12$ oilimmersion objective, and the mean diameter of 100 cells and their nuclei in each case was determined by measuring both the long and the short diameters with an eyepiece micrometer. Some selection was necessary to avoid those cells with folded cytoplasm, unusually distorted nuclei, and those in tight collections. As far as possible the measurable cells were consecutive. The mean diameter of these measurements was calculated for each case and this is the "mean diameter" referred to below. In addition, percentages of abnormally enlarged nuclei (greater than $14 \mu$ in diameter) and of binucleate cells were calculated from counts of 1,000 cells.

\section{Results}

Measurement of Diameters.-These are set out in the Table and Fig. 4. 
TABLE

AVERAGE DIAMETERS OF BUCCAL SQUAMOUS CELLS

\begin{tabular}{|c|c|c|c|}
\hline Disease Group & $\begin{array}{l}\text { No. of } \\
\text { Cases }\end{array}$ & $\begin{array}{c}\text { Average } \\
\text { Cytoplasmic } \\
\text { Diameter } \\
\text { and } \\
\text { Standard } \\
\text { Error }(\mu)\end{array}$ & $\begin{array}{l}\text { Average } \\
\text { Nuclear } \\
\text { Diameter } \\
\text { and } \\
\text { Standard } \\
\text { Error }(\mu)\end{array}$ \\
\hline $\begin{array}{l}\text { Tongue papillated : } \\
\quad \text { Normal control } \\
\text { Pernicious anaemia } \\
\text { Other megaloblastic anaem- }\end{array}$ & $\begin{array}{r}10 \\
5\end{array}$ & $\begin{array}{l}50 \cdot 11 \pm 1 \cdot 17 \\
51 \cdot 65 \pm 1 \cdot 17\end{array}$ & $\begin{array}{l}8 \cdot 64 \pm 0.17 \\
8 \cdot 66 \pm 0.08\end{array}$ \\
\hline $\begin{array}{l}\text { ias } \\
\text { All megaloblastic anaemias } \\
\text { Iron-deficiency anaemia }\end{array}$ & $\begin{array}{r}4 \\
9 \\
10\end{array}$ & $\begin{array}{l}51 \cdot 48 \pm 1 \cdot 37 \\
51.57 \pm 0.87 \\
46.46 \pm 0.94\end{array}$ & $\begin{array}{l}8 \cdot 93 \pm 0 \cdot 21 \\
8 \cdot 78 \pm 0 \cdot 08 \\
8 \cdot 94 \pm 0 \cdot 11\end{array}$ \\
\hline $\begin{array}{cccc}\text { Other cases } & \text { with } & \text { abnormal } \\
\text { tongues } & . & \ldots & .\end{array}$ & 4 & $43 \cdot 86 \pm 2 \cdot 62$ & $8 \cdot 83 \pm 0 \cdot 28$ \\
\hline $\begin{array}{l}\text { Tongue depapillated : } \\
\text { Pernicious anaemia } \\
\text { Other megaloblastic anaem- }\end{array}$ & 13 & $49 \cdot 32 \pm 1.49$ & $9 \cdot 92 \pm 0.27$ \\
\hline $\begin{array}{l}\text { ias } \\
\text { All megaloblastic anaemias } \\
\text { Iron-deficiency anaemia }\end{array}$ & $\begin{array}{r}7 \\
20 \\
10\end{array}$ & $\begin{array}{l}47 \cdot 33 \pm 2 \cdot 14 \\
48 \cdot 77 \pm 1 \cdot 22 \\
48 \cdot 55 \pm 1 \cdot 33\end{array}$ & $\begin{array}{r}10 \cdot 28 \pm 0 \cdot 15 \\
10 \cdot 10 \pm 0 \cdot 19 \\
9 \cdot 41 \pm 0 \cdot 16\end{array}$ \\
\hline $\begin{array}{ccc}\text { Other cases } & \text { with } & \text { abnormal } \\
\text { tongues } & . & \ldots\end{array}$ & 6 & $44.96=1.27$ & $9.39 \quad 0.16$ \\
\hline
\end{tabular}

Normal Buccal Cells.-Buccal squamous cells from a normal healthy person have a cytoplasmic diameter from $20 \mu$ to $80 \mu$, with a mean of about $50 \mu$. The nucleus is small and oval with a fine regular chromatin pattern (except when pyknotic) and a diameter varying from $5 \mu$ to $13 \mu$, with a mean of about $8.6 \mu$. Occasional binucleate cells are present. The cytoplasm frequently contains kerato-hyaline granules and often there is a perinuclear halo. The appearance of these cells is shown in Fig. 1.

Cells from Cases of Megaloblastic Anaemia.Many of the buccal cells from cases of megaloblastic anaemia have a normal appearance apart from the slight increase in nuclear diameter.

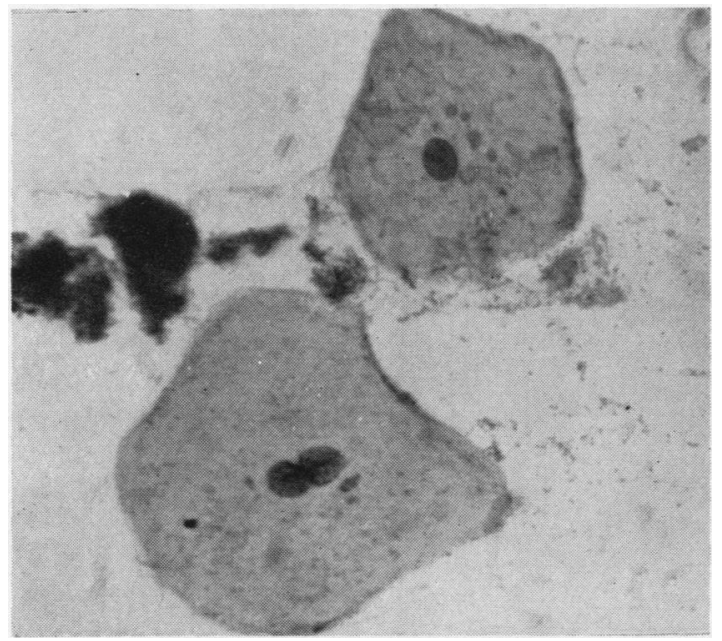

Fig. 1.-Normal buccal squamous cells. The lower one is binucleate and the other contains kerato-hyaline granules. $\times 400$.

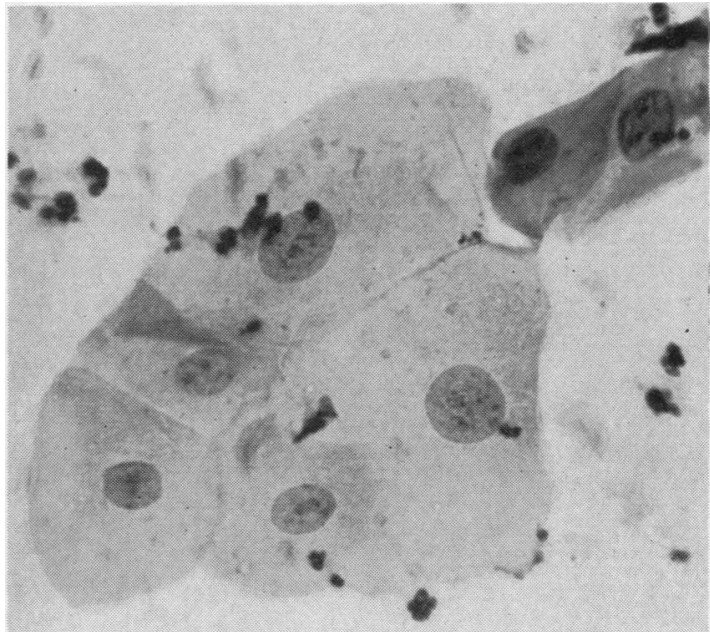

FIG. 2.-Buccal cells from a case of pernicious anaemia with a smooth tongue. All the nuclei are larger than normal and the two largest cells have "giant" nuclei, i.e., greater than $14 \mu$ in diameter. $\times 400$.

Occasional nuclei, however, are hyperchromatic with prominent nucleoli and a serrated nuclear membrane, but are not usually much enlarged. The greatly enlarged (giant) nuclei are commonly vesicular and round with a regular nuclear border (Fig. 2). The cytoplasmic diameter in these cells is rarely very large and is commonly even smaller than normal.

Measurements of cytoplasmic diameters showed close agreement with those of the normal series. The cases with normal tongues tended to have slightly larger diameters than normal, while in the group with depapillated tongues they were rather smaller (see Table). In only one case was there any considerable increase in size. In six cases examined 10 to 15 days after treatment with vitamin $B_{12}$ there was a decrease in diameter in five, while in the sixth case the tongue remained smooth in spite of treatment.

The nuclear diameters, on the other hand, were essentially normal in the cases with papillated tongues, but those with smooth tongues had much larger nuclei; the difference between the averages for this group (see Table) and that of the controls was highly significant $(\mathrm{P}=<0.001)$.

One patient with a normal tongue showed a high mean diameter, whereas two of them with smooth tongues had diameters within normal limits (Fig. 4). Five of the six patients examined after treatment showed the expected reversion towards normal; two had subnormal diameters after 10 and 15 days respectively. 
Cells from Cases of Iron-deficiency Anaemia.Changes in the buccal cells in iron-deficiency anaemia have not so far been reported. This study has shown that the cytoplasmic diameters in the 20 cases examined tended to be smaller than normal especially in 10 cases with papillated tongues (see Table). The difference between the average for this group of 10 and that of the normal controls is a significant one at the $5 \%$ level.

The mean nuclear diameters of the 10 cases with normal tongues were within normal limits although in two cases there was some enlargement. On the other hand, most of the cases with atrophy of the papillae showed nuclear enlargement (Fig. 4). In some cases the diameters were comparable to those seen in megaloblastic anaemia (Fig. 3) and the average for this group showed a statistically significant increase over normal $(P=<0.05)$.

Cases with Abnormal Tongues not Associated with Anaemia.-The 10 cases with abnormal or smooth tongues in the absence of anaemia in which buccal cells were measured all had normal haemoglobin values. (Six had completely depapillated tongues, two had thrush, one had leukoplakia of the tongue, and one had a painful tongue normal in appearance of unknown aetiology.)

In all but one of this miscellaneous group there was a smaller cytoplasmic diameter than normal and both the groups (see Table) showed a significantly smaller average diameter at the $5 \%$ level.

The nuclear diameters were within normal limits in three of the cases without epithelial atrophy of the tongue, and in two of those with a depapillated tongue (Fig. 4). The group without atrophy showed an average diameter which was essentially normal, whilst the group with smooth tongues (see Table) had a diameter which was significantly higher than normal $(P=<0.05)$.

Percentages of Nuclear Abnormalities.-Fig. 5 illustrates these in the patients and controls.

The most readily observed changes and those which are most easily measured are the greatly enlarged (giant) nuclei and the binucleate cells. These appeared to be more numerous in megaloblastic anaemia than in other conditions, and in order to verify this supposition the percentages of nuclei greater than $14 \mu$ in mean diameter and the cells with two or more nuclei in counts of 1,000 cells were found for each case. Fig. 5 shows the mean values for each group.

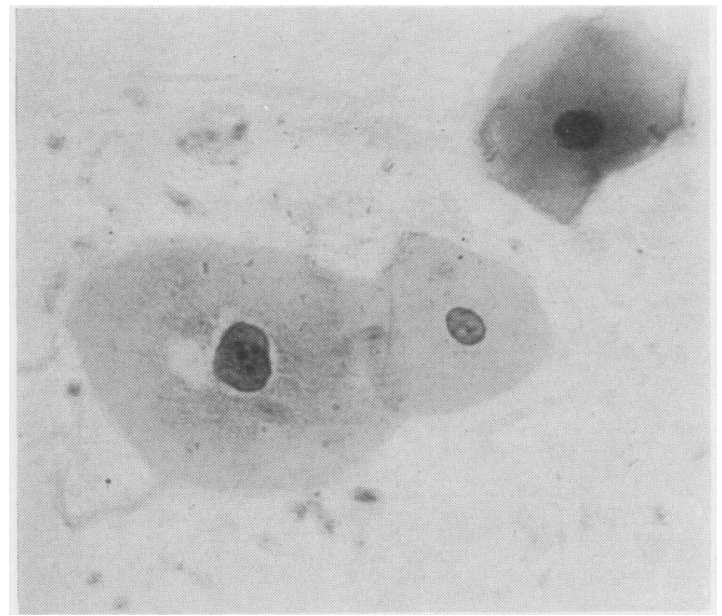

FIG. 3.-Buccal cells from a case of iron-deficiency anaemia with a smooth tongue. The largest cell has a "giant " nucleus which is also hyperchromatic with three prominent nucleoli and an irregular border. $\times 400$.

Nuclei Greater than $14 \mu$ in Diameter.-No nuclei of this size were seen in specimens from normal persons.

"Giant" nuclei were found in all cases of megaloblastic anaemia with smooth tongues. Two cases with near normal diameters showed quite frequent giant nuclei and small percentages were also found in five of the cases with papillated tongues, four of them having normal mean diameters.

None of the cases with iron-deficiency anaemia having normal tongues had abnormally large nuclei, but all but two of the group with smooth tongues showed them (Fig. 3).

Of the 10 cases without anaemia five with increased nuclear diameters also showed "giant" nuclei.

"Giant" nuclei, therefore, were present in the majority of cases with smooth tongues and in half of the cases of megaloblastic anaemia with normal tongues. Whilst many of the cases of megaloblastic anaemia had a high percentage of large nuclei (over $5 \%$ ) and the mean values (Fig. 5) show a striking difference from the means of the other groups, there is some overlap between the groups and no specific diagnostic value can be attached to the "giant" nuclei alone.

Multinucleation.-Cells with more than two nuclei were rarely seen. Graham and Rheault (1954) and Górz-Kardaszewicz (1956) have reported cells with five and nine nuclei respectively, although the photomicrographs of these 


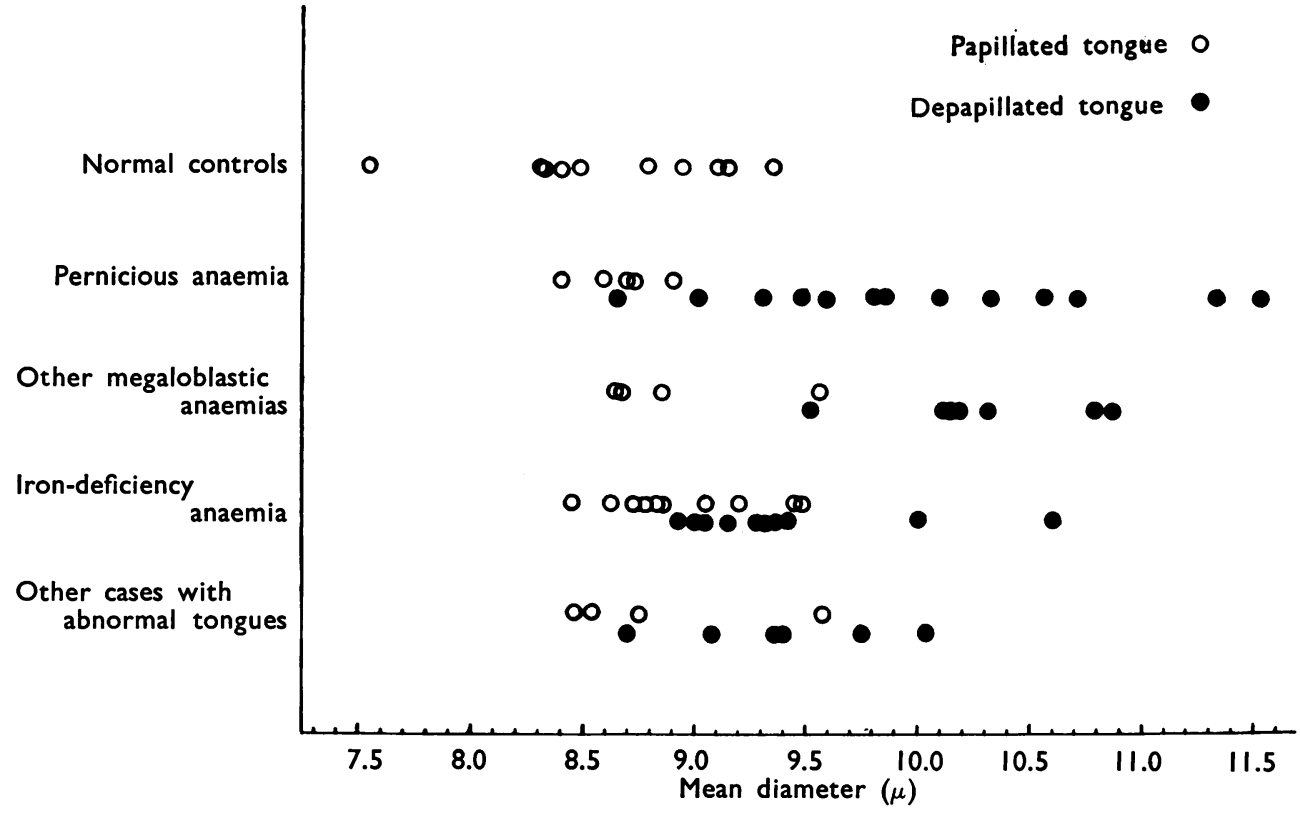

FIG. 4.-The mean nuclear diameters for each case examined.

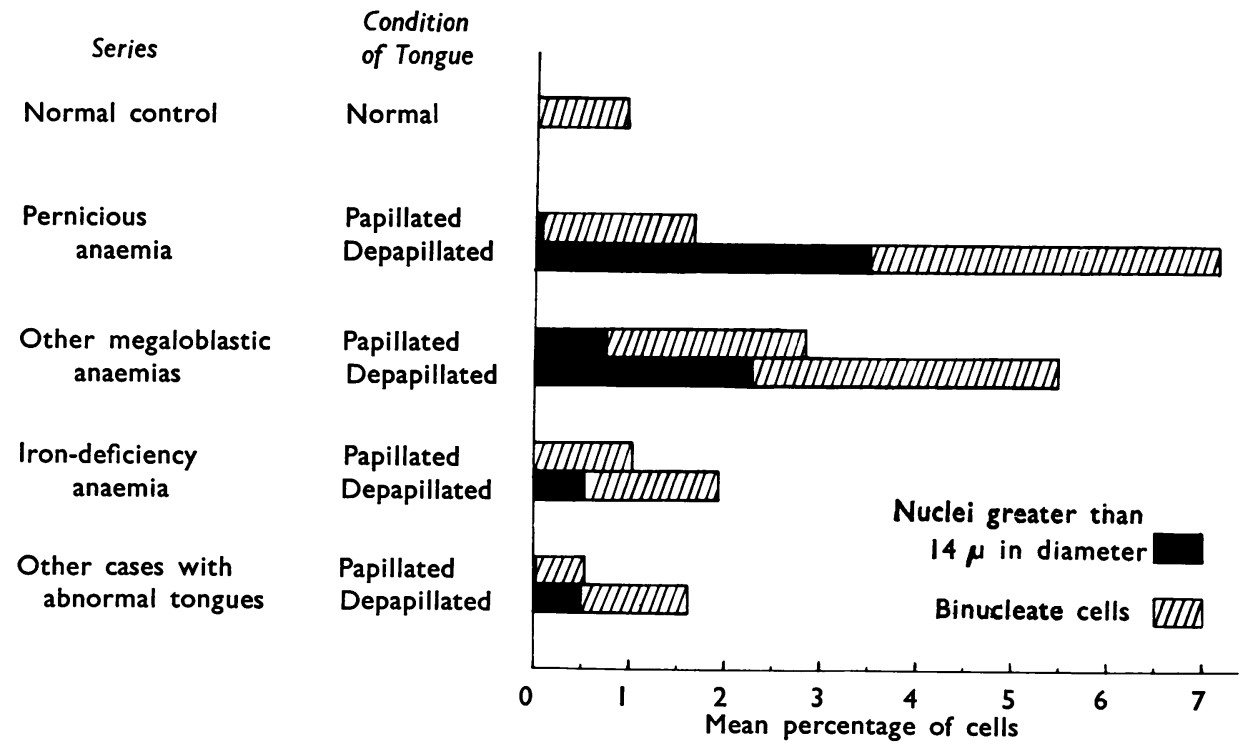

Fig. 5.-The mean percentage values of nuclei greater than $14 \mu$ in diameter and of binucleate cells in each group of cases. 
suggest that they may in fact have been cell clusters. An acceptable example has been published by Massey and Klayman (1955).

The percentages of binucleate cells calculated from counts of 1,000 cells again showed them to be more numerous in cases with megaloblastic anaemia although not necessarily correlated with the " giant" nuclei (Fig. 5). There was still some overlap between the normals and the other groups.

Other Abnormalities.-Nuclear abnormalities such as hyperchromatism with unevenly distributed chromatin and irregular nuclear membrane are qualitative, and interpretation will vary from one observer to another. Such abnormalities may be more frequent in cases with megaloblastic anaemia, but are not always present and do not appear to be specific.

\section{Conclusions}

Graham and Rheault's (1954) initial observation, later confirmed by Boen (1957), of the enlargement of the cytoplasmic diameters in buccal squamous cells in cases with pernicious anaemia was not confirmed in this investigation.

The cells in pernicious anaemia were not much changed in size from those in normal persons and tended to be smaller in those cases with atrophy of the lingual epithelium. This tendency towards a smaller cytoplasmic size was more apparent in cases with iron-deficiency anaemia and certain other diseases. In addition the cytoplasmic diameter decreased still further in pernicious anaemia after treatment.

We have confirmed that in many cases of megaloblastic anaemia the buccal cell nucleus is abnormally large and that there are other nuclear abnormalities. In the majority of cases, however, these abnormalities were associated with atrophy of the lingual epithelium and were also present in cases with certain other diseases where a smooth tongue was present. Farrant (1958) has described one such case without anaemia, and lingual atrophy may account for the six cases which did not have megaloblastic anaemia described by Massey and Klayman (1955).

Cases in our series of megaloblastic anaemia with normal tongues did not show nuclear enlargement, and it was not invariable in the cases with smooth tongues. Boen (1957) has also described three cases of pernicious anaemia with normal nuclear diameters. In such cases there may be other nuclear abnormalities, also nonspecific, but usually much more marked in megaloblastic anaemia.
Gardner (1956) described nuclear fragmentation and nuclear haloes as additional abnormalities in tropical sprue. Nuclear fragments in the cytoplasm were never seen in our preparations, and Gardner may have been observing kerato-hyaline granules. Percentages of cells containing these vary considerably in each specimen, and we have found no correlation with the disease or the state of the tongue (thus confirming Górz-Kardaszewicz, 1956). Perinuclear haloes are not spesific for megaloblastic anaemia and are a normal feature of buccal cells (Ziskin and Moulton, 1948). Certain cases did show extreme examples of this phenomenon, and our case of tropical sprue was one of them.

Whilst concluding that percentage values of such nuclear abnormalities as gigantism and binucleation are not an adequate diagnostic test for megaloblastic anaemia in all cases, these may be high enough to assist in the diagnosis. Boen, Molhuysen, and Steenbergen (1958) have demonstrated such an instance.

It is evident from our series that the abnormal enlargement of the buccal cell nucleus is not directly correlated with the smoothness of the tongue. This is illustrated by the finding of this abnormal change in cells from cheek scrapings (Górz-Kardaszewicz, 1956 ; Farrant, 1958). It seems that these abnormalities appear at a stage in the deficiency state when the tongue also (in most cases) becomes clinically abnormal. No attempt was made to classify the degree of lingual atrophy, but it is of interest that most of the cases in the "smooth" group with normal or near-normal nuclear diameters did not have completely depapillated tongues. A method of indexing the degree of depapillation, such as that of DiPalma (1946), would possibly give a closer correlation.

It appears, therefore, that in megaloblastic anaemia the abnormality in cellular metabolism, whose nature is still not fully understood, at the same time causes the megaloblastic transformation in the red cell precursors, the gigantism of the granular leucocytes, and the nuclear abnormalities of the epithelial cells (of which the buccal cells are the most strikingly affected). The enlargement of the nucleus of the buccal squamous cell may be produced by other metabolic defects such as iron-deficiency, but the present methods of examination cannot distinguish between the different causes.

\section{Summary}

Mean cytoplasmic and nuclear diameters of salivary squamous cells were measured in 69 
persons. Eighteen of these had pernicious anaemia, 11 had other megaloblastic anaemias, 20 had iron-deficiency anaemia, 10 had abnormal tongues not associated with anaemia, and 10 were normal controls. Thirty-six of the patients had smooth tongues.

The cytoplasmic diameters of buccal cells from cases of pernicious anaemia were not enlarged but tended to be smaller than in normal healthy persons. In other megaloblastic anaemias, irondeficiency anaemia, and in some other diseases not associated with anaemia but having abnormal tongues, the cytoplasmic diameter also appeared to be abnormally small.

The nuclei of buccal cells showed a distinctly enlarged diameter in those cases of megaloblastic anaemia in which there was lingual atrophy. Cases of iron-deficiency anaemia also sometimes showed this nuclear enlargement in the presence of a smooth tongue, and a high nuclear diameter is by no means specific for any particular cause of lingual atrophy. However, the highest figures were found in pernicious anaemia.

Specific nuclear abnormalities such as "giant" nuclei and binucleation were more common in megaloblastic anaemia than in other disease groups with smooth tongues. A small percentage of abnormal nuclei could be seen in cases of megaloblastic anaemia with normal tongues. These abnormalities are not a specific diagnostic test for the megaloblastic anaemias but may assist diagnosis when they are present to a marked degree.

My thanks are due to the medical staff of the United Oxford Hospitals for providing me with specimens and details of patients under their care; to Mrs. D. Jackson for her assistance with the photography; and to Mr. N. T. J. Bailey for his advice on the statistics.

I am also grateful to Dr. A. H. T. Robb-Smith for correcting the manuscript and in particular to $\mathrm{Dr}$ A. I. Spriggs for all the advice and help given during this investigation.

The work was carried out while receiving a grant from the British Empire Cancer Campaign.

\section{REFFRENCES}

Boddington, M. M., and Spriggs, A. I. (1959). J. clin. Path., 12, 228. Boen, S. T. (1957). Acta med. scand., 159, 425.

Molhuysen, J. A., and Steenbergen, J. (1958). Lancet, 2, 294. DiPalma, J. R. (1946). Arch. intern. Med., 78, 405.

Farrant, P. C. (1958). Lancet, 1, 830.

Gardner, F. H. (1956). J. Lab. clin. Med., 47, 529.

Górz-Kardaszewicz, S. (1956). Pat. pol., 7, 373.*

Graham, R. M., and Rheault, M. H. (1954). J. Lab. clin. Med., 43, 235.

Massey, B. W., and Klayman, M. I. (1955). Amer. J. med. Sci., 230, 506.

Rubin, C. E. (1955). Gastroenterology, 29, 563.

(1956). Ann. N.Y. Acad. Sci., 63, 1377.

Ziskin, D. E., and Moulton, R. (1948). J. clin. Endocr., 8 , 146.

* As it is only available in Polish the following summary of the publication by Górz-Kardaszewicz (1956) is given.

From 10 to 15 cheek scrapings at three- to four-day intervals were taken from $1 \mathrm{~cm}$. below the right parotid duct in each patient, were taken from $1 \mathrm{~cm}$. below the right parotid duct in each patient, and examined in wet-fixed films stained with haematoxylin and eosin. Percentages of abnormal cells were calculated in each of 32
patients with anaemia (22 pernicious anaemia) and in 10 normal males and 10 normal females. The abnormalities counted were large cells with normal nuclei, large nuclei in normal cells, multinucleate cells, cells containing cytoplasmic granules, and anucleate cells.

The results were tabulated and showed about $10 \%$ of abnormal cells in pernicious anaemia. Cells with a total diameter above $91 \mu$ accounted for $4 \%$ of this increase, those with nuclei above $16 \mu$ in diameter $2 \%$, and binucleate cells $4 \%$. The abnormal enlargement persisted in a smaller percentage of cells in 16 cases after treatment. The number of cells with granules and anucleate cells was not abnormally high.

Gorr-Kardaszewicz postulates that the same factor controls both the changes in the epithelium and in the marrow because gigantism and multinucleation can be found in cells obtained from all accessible regions of the body, but no data for this hypothesis are given. 